\title{
New Dimensions of Postpurchase Behavior in the Service Environment: Consumer Behavior Toward Uber after Consumer Ratings: An Abstract
}

\author{
Kathryn Woodbury Zeno and Gladys Torres-Baumgarten
}

\begin{abstract}
Analyzing consumer postpurchase behavior is a common and ongoing practice. Advanced technology utilized by consumers has facilitated more convenient methods to input feedback and to provide feedback that is immediate in nature. Postpurchase behavior has been studied extensively in the packaged goods industry and in particular the service industry where service quality gaps identify potential explanations for postpurchase behavior. This study argues that the service quality evaluation model does not adequately address the new dimension of provider ratings of the consumer. Specifically, the impact of the provider's rating of the consumer on the consumer's perceived service quality is not understood, nor is the impact of the provider rating of the consumer on consumer postpurchase usage behavior and consumer attitude toward the provider. Expected expansion of formal systems within the service environment for providers to rate consumers supports the need for further study and empirical analysis to advance understanding of service quality evaluation.
\end{abstract}

References Available Upon Request

K. W. Zeno $(\bowtie) \cdot G$. Torres-Baumgarten

Ramapo College of New Jersey, Mahwah, NJ, USA

e-mail: kzeno@verizon.net; torresbaumgarten@gmail.com 